\title{
Treatment of asthma during pregnancy: more solid evidence needed
}

\section{Mario Cazzola, ${ }^{1}$ Maria Gabriella Matera²}

In this issue of Thorax, a paper by Tata and colleagues ${ }^{1}$ assesses the association between maternal asthma and gestational exposure and asthma medications with the risk of congenital malformation in offspring using The Health Improvement Network primary care database (see page 981). Their findings showed that gestational exposure to commonly used asthma medications seems to be safe, although a moderate teratogenic risk of cromones cannot be excluded. This is important information for many doctors, mainly pulmonologists and allergologists involved in the treatment of asthma in pregnant women. It indicates that we can approach the pregnant patient with asthma in the traditional manner, without major concerns and using all the available treatment options with the exclusion of cromones which, in any case, currently represent an unusual therapeutic choice.

The results of this study enable us to reassure our pregnant patients. We have all found that one of the most complicated aspects of the work of a chest physician is to convince a pregnant patient with asthma to adhere to prescribed therapy. Several surveys have shown that women decrease and/or stop asthma medications during early pregnancy, probably because they are concerned about the safety of asthma medications during pregnancy. ${ }^{2-4}$ Conversely, physicians appear to be reluctant to prescribe asthma medications for pregnant women. A multicentre study found that pregnant women with asthma were significantly less likely to be prescribed corticosteroids in the emergency department: only $44 \%$ of pregnant women were treated with corticosteroids

\footnotetext{
${ }^{1}$ Unit of Respiratory Medicine, Department of Internal Medicine, University of Rome "Tor Vergata", Rome, Italy: ${ }^{2}$ Unit of Pharmacology, Department of Experimental Medicine, Second University of Naples, Naples, Italy

Correspondence to: Professor M Cazzola, Cattedra di Malattie Respiratorie, Dipartimento di Medicina Interna, Università di Roma "Tor Vergata", Via Montpellier 1, 00133 Roma, Italy; mario.cazzola@uniroma2.it
}

compared with 66\% of non-pregnant women. ${ }^{5}$ Those who were admitted to hospital were less likely to be treated with corticosteroids at discharge and were almost three times more likely to experience a subsequent exacerbation than nonpregnant women. ${ }^{5}$ This is undoubtedly an important issue given that it is estimated that about $18 \%$ of all pregnant women with asthma have at least one visit to the emergency department and as many as $62 \%$ of pregnant subjects with acute severe asthma require hospitalisation. ${ }^{6}$

In theory, pregnant women should not receive drugs, especially during the first 3 months of gestation. In reality, however, asthma in pregnancy needs to be treated and drugs are necessary, since uncontrolled asthma represents a risk factor to both the mother and the fetus.' Murphy et $a l^{8}$ recently conducted a systematic review of the literature for publications related to exacerbations during pregnancy. During pregnancy, exacerbations of asthma which require medical intervention occur in about $20 \%$ of women, with approximately $6 \%$ of women being admitted to hospital. Women who have a severe exacerbation during pregnancy are at a significantly increased risk of having a low birthweight baby compared with women without asthma, which may predispose to diseases in later life. On the other hand, adequately controlled asthma does not seem to be associated with adverse maternal and fetal outcomes. Consequently, US guidelines for the management of asthma during pregnancy ${ }^{9}$ recommend a stepwise approach to treatment with the goal of maintaining control of maternal asthma, as the risks of asthma exacerbations are greater than the risks associated with the use of asthma medications during pregnancy. In effect, increasing evidence supports the perception of the safety of inhaled corticosteroids for the treatment of asthma during pregnancy with regard to the likelihood of congenital malformation. ${ }^{10}$ Moreover, use of inhaled $\beta$ agonists, inhaled corticosteroids and theophylline do not appear to increase perinatal risks in pregnant women with asthma, whereas oral corticosteroid use seems to be significantly associated with preterm birth at less than 37 weeks' gestation. $^{11}$

It is not clear whether oral corticosteroids directly cause premature birth or whether they serve as a marker for asthma sufficiently severe or uncontrolled to cause prematurity. ${ }^{11}$ However, this is unimportant because systemic corticosteroids, intravenous or oral, should be administered to patients suffering from an acute asthma exacerbation who show no improvement with the initial bronchodilator therapy and almost always to those with moderate to severe exacerbations. ${ }^{12}$ In any case, the British Thoracic Society guidelines $^{13}$ clearly state that medical management is identical for pregnant and non-pregnant women and oral steroids should be given in appropriate doses if clinically indicated. This need for systemic corticosteroids strengthens our opinion that complete control of symptoms and prevention of exacerbations must be the primary objectives when managing a pregnant patient with asthma. ${ }^{14}$

However, many reports have documented the risks associated with the use of asthma medications during pregnancy. A population-based case-control study that included cases of orofacial clefts, conotruncal heart defects, neural tube defects and limb reduction defects suggested a possible causal association between cleft lip and palate and maternal corticosteroid use during the periconceptional period (1 month before to 3 months after conception). ${ }^{15}$ Moreover, in another controlled study, the risk of gastroschisis in the offspring of women treated with bronchodilators during the periconceptional period was approximately twice that of women not using bronchodilators. ${ }^{16}$ This positive association persisted when women taking these medications outside the periconceptional period were added to the reference group. ${ }^{16} \mathrm{~A}$ recent analysis of data extracted from the Swedish Medical Birth Register identified 24369 women with 24750 infants who reported the use of anti-asthma drugs at the first maternal healthcare visit (usually weeks 10-12) and 7778 women with 7963 infants who received a prescription for anti-asthma drugs during pregnancy from a maternal healthcare centre. A number of negative effects were reported in the neonate when the mother used antiasthma drugs during pregnancy, all of which were relatively severe. These 
included preterm birth, low birth weight, small-for-gestational age and neonatal symptoms of icterus, hypoglycaemia and respiratory problems. ${ }^{17}$ The same analysis showed an increased risk of congenital malformation among infants born to women who used anti-asthma drugs in early pregnancy. The increase in risk was small and it is unclear if it was due to the asthma itself, to residual confounding, or to the drugs used. It seemed to occur mainly in women who used three or more anti-asthma drugs and therefore probably had relatively severe asthma. ${ }^{18}$ The increase in malformation rate appears to be associated with three conditions: relatively severe heart defects, orofacial clefts (notably median cleft palate) and anal atresia. $^{18}$ These findings indicate that there is an effect, although small, on the infants of mothers who use anti-asthma drugs during pregnancy.

There is a need for more solid evidence but, unfortunately, there is limited information on the long-term efficacy and safety of currently approved asthma medications in pregnant subjects, largely because traditional double-blind placebocontrolled research is unethical in pregnant women. Given the lack of current and valid data, we believe that no correct implications for practice can be drawn from systematic reviews.

The lack of certainty about how to treat a pregnant patient with asthma leaves us in doubt as to what to do, for the obvious ethical but also legal implications of our choices. Nonetheless, we believe that uncontrolled asthma in pregnant women can result in perinatal complications and exacerbations which can be life-threatening for the mother and fetus. Because these risks are greater than those of the adverse effects caused by controller medication use, we strongly support the opinion that women with asthma should receive controller therapy during pregnancy. In effect, this is what we do in everyday practice, fortunately without any negative result, at least until today, probably because we only prescribe those asthma controller medications that fall within pregnancy category B and only long-acting $\beta_{2}$ agonists between those that fall within pregnancy category $C$ of the US Food and Drug Administration (FDA) pregnancy category ratings for asthma controller medications. ${ }^{19}$ The paper by Tata and colleagues ${ }^{1}$ supports our behaviour, with the exception of cromones which have been rated pregnancy category B by the FDA based primarily on safety in animal reproduction studies. However, this is not an important issue because cromones have not been prescribed for a long time.

Competing interests: MC has received fees for speaking and consulting and/or financial support for attending meetings from Abbott, AstraZeneca, Boehringer Ingelheim, Chiesi Farmaceutici, Dey, Encysive, GSK, Keryos, Lallemand, Menarini Farmaceutici, Novartis, Nycomed, Pfizer, Sanovel and Valeas. MGM has received fees for consulting and/or financial support for attending meetings from AstraZeneca, Boehringer Ingelheim, Encysive, GSK, Novartis and Pfizer.

Thorax 2008;63:944-945. doi:10.1136/thx.2008.104463

\section{REFERENCES}

1. Tata LJ, Lewis SA, McKeever TM, et al. Effect of maternal asthma, exacerbations and asthma medication use on congenital malformations in offspring: a UK population-based study. Thorax 2008;63:981-7.

2. Chambers K. Asthma education and outcomes for women of childbearing age. Case Manager 2003;14:58-61.

3. Enriquez R, Wu P, Griffin MR, et al. Cessation of asthma medication in early pregnancy. Am J Obstet Gynecol 2006;195:149-53.
4. Wendel PJ, Ramin SM, Barnett-Hamm C, et al. Asthma treatment in pregnancy: a randomized controlled study. Am J Obstet Gynecol 1996;175:150-4.

5. Cydulka RK, Emerman CL, Schreiber D, et al. Acute asthma among pregnant women presenting to the emergency department. Am J Respir Crit Care Med 1999;160:887-92.

6. Enriquez R, Griffin MR, Carroll KN, et al. Effect of maternal asthma and asthma control on pregnancy and perinatal outcomes. J Allergy Clin Immunol 2007; 120:625-30.

7. National Asthma Education Program Report of the Working Groups on Asthma and Pregnancy. Management of asthma during pregnancy. NIH Publication No 93-3279A. Bethesda, MD: National Institutes of Health, 1993.

8. Murphy VE, Clifton VL, Gibson PG. Asthma exacerbations during pregnancy: incidence and association with adverse pregnancy outcomes. Thorax 2006;61:169-76.

9. NAEPP Expert Panel Report 3 (EPR-3). Guidelines for the diagnosis and management of asthma: summary report 2007. J Allergy Clin Immunol 2007; 120:S94-138.

10. Blais L, Beauchesne M-F, Rey É, et al. Use of inhaled corticosteroids during the first trimester of pregnancy and the risk of congenital malformations among women with asthma. Thorax 2007;62:320-8.

11. Schatz M, Dombrowski MP, Wise R, et al. The relationship of asthma medication use to perinata outcomes. J Allergy Clin Immunol 2004;113:1040-5.

12. Hanania NA, Cazzola M. Acute respiratory failure during pregnancy. Eur Respir Mon 2006;36:241-58.

13. British Thoracic Society/Scottish Intercollegiate Guidelines Network. British guideline on asthma management: a national clinical guideline. Thorax 2003;58(Suppl I):i47-58.

14. Liccardi G, Cazzola M, Canonica GW, et al. General strategy for the management of bronchial asthma in pregnancy. Respir Med 2003;97:778-89.

15. Carmichael SL, Shaw GM. Maternal corticosteroid use and risk of selected congenital anomalies. Am J Med Genet 1999;86:242-4.

16. Lin S, Munsie JP, Herdt-Losavio ML, et al. Maternal asthma medication use and the risk of gastroschisis. Am J Epidemiol 2008;168:73-9.

17. Källén B, Otterblad Olausson P. Use of anti-asthmatic drugs during pregnancy. 2. Infant characteristics excluding congenital malformations. Eur J Clin Pharmacol 2007:63:375-81.

18. Källén B, Otterblad Olausson P. Use of anti-asthmatic drugs during pregnancy. 3. Congenital malformation in the infants. Eur J Clin Pharmacol 2007:63:383-8.

19. Gluck JC, Gluck PA. Asthma controller therapy during pregnancy. Am J Obstet Gynecol 2005;192:369-80. 